\title{
Experimental Acanthamoeba keratitis: II. Immunohistochemical evaluation
}

\author{
D F P Larkin, D L Easty
}

\begin{abstract}
In a Wistar rat experimental model of Acanthamoeba keratitis immunohistochemical techniques were used to analyse the host cellular response. The inflammatory cell profile was observed to change at intervals. In tissue sections the cellular response consisted of neutrophils on the first day but predominantly macrophages on the following days. Some $\mathbf{T}$ lymphocytes but no $B$ lymphocytes were observed.
\end{abstract}

The free-living amoeba Acanthamoeba causes infection at two distinct sites. It was first demonstrated to cause granulomatous encephalitis: this occurs in chronically ill or immunocompromised patients and is usually fatal. ${ }^{1}$ Infection of the cornea later became recognised and is now more frequently diagnosed. Acanthamoeba may be cultured from corneal scrape or biopsy specimens, or may be demonstrated in tissue sections. The amoeba causes painful blinding keratitis and, in contrast to encephalitis, is usually seen in healthy people who wear contact lenses. ${ }^{23}$ Acanthamoeba keratitis typically has a chronic progressive course, with stromal infiltration and frequent failures of medical and surgical treatment. ${ }^{4}$

The reasons why this organism of low virulence causes progressive ocular infection in normal hosts, and why keratitis often responds poorly to agents shown in vitro to be effective against the cultured isolate are unknown. Study of the host immune response to Acanthamoeba infection is very limited because only corneal transplantation specimens are available for study; such patients have in most cases been intensively treated with anti-inflammatory agents prior to surgery. Consequently, available reports ${ }^{46}$ describe the late stages of the disease, probably modified by drug therapy.

Most pathological reports describe an acute inflammatory cell infiltrate in the stroma, with in some cases a sparse added lymphocyte component. ${ }^{45}$ The report on two patients by Mathers and colleagues was the first to define by immunohistochemical methods the inflammatory response in Acanthamoeba keratitis. ${ }^{6}$ They found that the inflammatory cell population comprised $80-100 \%$ neutrophils and macrophages near the site of active corneal ulceration.

The immune response of the host is probably important in development of this infection, and an analysis of the inflammatory cell types within the cornea subsequent to infection provides further understanding of the mechanisms of disease. A rat model of experimental Acanthamoeba keratitis has been established in which the infection is induced by intrastromal injection of the cyst form of Acanthamoeba. ${ }^{7}$ Untreated tissue can be studied pathologically at specified intervals after disease induction. Conventional histological techniques and immunohistochemical staining with monoclonal antibodies against cell markers have been used to characterise the constituent cell types.

\section{Materials and methods}

ACANTHAMOEBA INOCULATION AND CLINICAL EXAMINATION

The detailed procedure for induction of experimental keratitis has been previously reported. ${ }^{7}$ Briefly; an axenic cyst suspension of a human keratitis isolate ( $A$ polyphaga, strain Shi) was prepared at a concentration of $1 \times 10^{6} / \mathrm{ml}$ in Page's amoeba saline. $1 \mu \mathrm{l}$ of this suspension was inoculated by intrastromal injection into the right cornea of outbred $125 \mathrm{~g}$ male Wistar rats under general anaesthesia. The concentration of this suspension was predetermined as the dose necessary to induce reproducible clinical keratitis.

On days $1,3,5,7$, and weekly thereafter until 12 weeks following inoculation the rats were examined under general anaesthesia by slitlamp. Corneal inflammation was graded on a scale of $0-3$ for opacity (grade 0 being normal and grade 3 indicating dense corneal opacity), and the mean score for all infected corneas at each time interval was calculated. All procedures described conformed to the ARVO resolution on the Use of Animals in Research.

\section{PREPARATION OF WAX SECTIONS}

Two rats were killed by intraperitoneal injection of $60 \mathrm{mg}$ pentobarbitone on days $1,3,7,14,21$, 42 , and 84 days after inoculation. The right eye was enucleated; the cornea was dissected and halved. One half was fixed for $24 \mathrm{~h}$ in neutral buffered formaldehyde, embedded in wax, and 6 $\mu \mathrm{m}$ sections cut with a microtome. Sections were stained, as previously described, with haematoxylin and eosin or rabbit antiAcanthamoeba antibody (staining trophozoite or cyst forms brown).?

\section{PREPARATION OF FROZEN SECTIONS}

Hemicorneas from eyes enucleated as described above were mounted in embedding compound (Tissue-Tek OCT, Miles Scientific, Naperville, II) and snap-frozen in liquid nitrogen. Sections of $6 \mu \mathrm{m}$ thickness were cut with a cryostat (2800 Frigocut-E, Reichert-Jung) at $-30^{\circ} \mathrm{C}$. Sections were mounted on polylysine-coated
Correspondence to: Mr D F P Larkin, Moorfields Eye Hospital, City Road, London ECIV 2PD.

Accepted for publication 20 December 1990
University Department of Eye Hospital, Lower Maudlin Street, Bristol 
Table 1 Monoclonal antibodies and incubations used in staining of corneas

\begin{tabular}{lllll}
\hline Antibody & Specificity & Dilution & Duration & Temperature \\
\hline ED2 & Macrophages $^{8}$ & $1: 20,000$ & $16 \mathrm{~h}$ & $4^{\circ} \mathrm{C}$ \\
MRC OX-19 & Pan-T cell $^{9}$ & $1: 100$ & $16 \mathrm{~h}$ & $4^{\circ} \mathrm{C}$ \\
MRC OX-33 & Pan-B cell $^{10}$ & $1: 900$ & $16 \mathrm{~h}$ & $4^{\circ} \mathrm{C}$ \\
MRC OX-39 & ॠnterleukin-2 receptor $^{11}$ & $1: 250$ & $30 \mathrm{~min}$ & $37^{\circ} \mathrm{C}$ \\
MRC OX-21 & tHuman C3b inactivator $^{12}$ & $1: 2$ & - & - \\
\hline
\end{tabular}

All monoclonal antibodies (Serotec Ltd, Oxford, England) were prepared from mouse hybridoma ascites fluid, except $\mathrm{OX}-21$, which was prepared from tissue culture supernatant.

$\star$ Designating activated T-cells.

+ Negative control, reacts with human but not rat tissue.

glass slides, air dried, immersed in acetone for 5 seconds, and frozen at $-85^{\circ} \mathrm{C}$ for storage.

\section{IMMUNOHISTOCHEMICAL STAINING OF FROZEN SECTIONS}

Sections were stained by the peroxidase antiperoxidase technique. Frozen sections were fixed in acetone for $10 \mathrm{~min}$, air dried, and washed in distilled water for $30 \mathrm{~min}$. Endogenous peroxidase activity was blocked by inoculation with $\mathbf{0} \cdot 3 \%$ hydrogen peroxide for $30 \mathrm{~min}$. After washing in phosphate-buffered saline (PBS), non-specific background staining was blocked by incubation with 1:5 normal rabbit serum in PBS for $30 \mathrm{~min}$. Excess serum was blotted from sections, and mouse hybridoma monoclonal antibody was then added at specific dilutions, incubation times, and temperatures (Table 1). The sections were then washed and incubated with 1:50 secondary antibody (diluted with 1:10 normal rat serum) for $30 \mathrm{~min}$ at room temperature. Sections were again washed and incubated with 1:50 horseradish peroxidase antiperoxidase (PAP) complex (diluted with 1:10 normal rat serum). After again washing with PBS, sections were incubated with a chromagen to identify antibody binding. For this purpose 3 , 3'-diaminobenzidine (Sigma Chemical Co) was used, mixed with $\mathrm{H}_{2} \mathrm{O}_{2}$ in $0 \cdot 1 \mathrm{M}$ trometamol (Tris) buffer, giving a brown end product. After incubation for 7 minutes sections were washed in tap water for 5 minutes, counterstained with haematoxylin, and mounted.

Lymph node sections from normal Wistar rats, processed identically to the experimental sections, were used as positive controls. Lymph nodes contain a variety of inflammatory cell subtypes: thus node sections were moderately positive specimens, sensitive to variations in performance of the method. Experimental corneal sections for use as negative controls received, in place of primary antibody, an antibody which was known not to react with antigen in rat tissue. A monoclonal antibody against a human inflammatory product, MRC OX-21 (Serotec Ltd, Oxford, England), was used at dilution $1: 2$. This is a mouse monoclonal antibody against human $\mathrm{C} 3 \mathrm{~b}$ inactivator ${ }^{12}$ and does not react with rat tissues.

\section{QUANTITATIVE ANALYSIS OF SECTIONS}

The positively stained inflammatory cells or Acanthamoeba in the stroma of the central cornea were counted with a graticule at $400 \times$ magnification. Three adjoining fields in each of two corneas from rats killed at the same interval were evaluated and a mean count calculated.

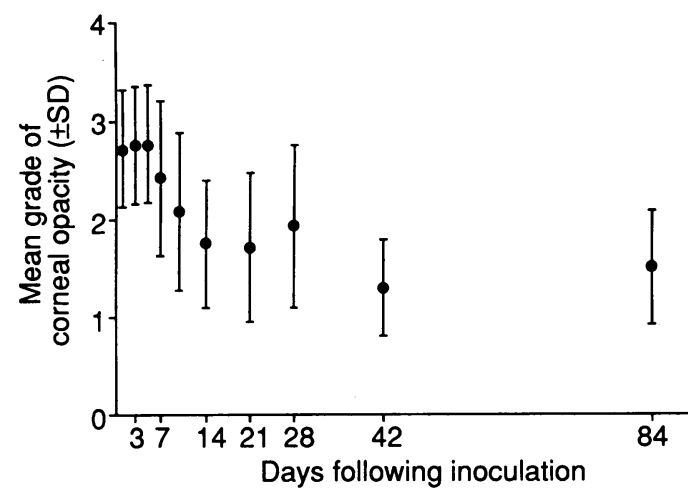

Figure 1 Grade of corneal opacity at intervals after induction of infection. The mean grade of opacity of all infected corneas examined on that day is shown.

\section{Results}

\section{CLINICAL EVOLUTION OF KERATITIS}

The inflammatory infiltration of the right cornea following Acanthamoeba inoculation as determined by slit-lamp examination is shown in Fig 1. Animals developed a stromal opacity which was granular in character. Corneal epithelial defects, vascularisation, perforation, and evidence of intraocular inflammation were not observed. Stromal opacity was maximal for the first seven days following inoculation and gradually declined after that time.

\section{IMMUNOPEROXIDASE STAINING OF}

ACANTHAMOEBA IN TISSUE SECTIONS

Numbers of staining amoebae are shown in Table 2. An increasing proportion of trophozoite Acanthamoeba was observed in sections at intervals following inoculation.

\section{CELLULAR COMPOSITION OF THE INFLAMMATORY} INFILTRATE

Inflammatory cell types within the central stroma were identified by haematoxylin and eosin staining of neutrophils and by monoclonal antibody staining of surface antigens on macrophages, B cells, $T$ cells, and activated $T$ cells (Table 1). The relative number and proportions of inflammatory cells are shown in Table 3 and Figs 2A, B.

On day 1 neutrophils were the only inflammatory cell identified. A negligible number of other cell types staining with haematoxylin and eosin, which did not appear to be neutrophils, were not identified by staining with any of the monoclonal antibodies. On day three a similar total number of cells were seen but a proportion of these were macrophages.

Table 2 Acanthamoeba in central corneal stroma

\begin{tabular}{rcc}
\hline Day & Number of amoebae (mean) & $S E$ \\
\hline 1 & $8 \cdot 7$ & $1 \cdot 5$ \\
3 & $12 \cdot 9$ & $1 \cdot 3$ \\
7 & $6 \cdot 1$ & $0 \cdot 6$ \\
21 & $2 \cdot 0$ & $0 \cdot 7$ \\
42 & $0 \cdot 6$ & $0 \cdot 3$ \\
84 & $1 \cdot 3$ & $0 \cdot 3$ \\
\hline
\end{tabular}

Trophozoite and cyst forms of Acanthamoeba were stained by immunoperoxidase technique using rabbit anti-Acanthamoeba antibody. $\mathrm{SE}=$ =standard error. 
Table 3 Inflammatory cell types in the central stroma of corneas infected by Acanthamoeba

\begin{tabular}{|c|c|c|c|c|c|c|c|c|c|c|c|}
\hline Day & $\begin{array}{l}\text { Neutro } \\
\text { cells }\end{array}$ & $\begin{array}{l}\text { phils } \\
\%\end{array}$ & $\begin{array}{l}\text { ED2+ } \\
\text { cells }\end{array}$ & $\%$ & $\begin{array}{l}\text { OX-33+ } \\
\text { cells }\end{array}$ & + & $\begin{array}{l}\text { OX-19- } \\
\text { cells }\end{array}$ & + & $\begin{array}{l}\text { OX }-39+ \\
\text { cells }\end{array}$ & + & Total \\
\hline 1 & 12 & 100 & 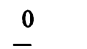 & - & 0 & - & 0 & - & 0 & - & 12 \\
\hline 3 & $\begin{array}{l}10 \\
(1 \cdot 4)\end{array}$ & 77 & $\begin{array}{l}3 \\
(0 \cdot 8)\end{array}$ & 23 & $\begin{array}{c}0 \\
-\end{array}$ & - & 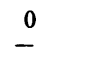 & - & 0 & - & 13 \\
\hline 7 & $\begin{array}{c}6 \\
(0 \cdot 5)\end{array}$ & 15 & $\begin{array}{l}24 \\
(6 \cdot 3)\end{array}$ & 63 & 0 & - & $\begin{array}{c}8 \\
(2 \cdot 7)\end{array}$ & 22 & 0 & - & 38 \\
\hline 14 & $\begin{array}{l}6 \\
(1 \cdot 0)\end{array}$ & 11 & $\begin{array}{l}38 \\
(1 \cdot 3)\end{array}$ & 68 & 1 & 4 & 11 & 20 & $\begin{array}{c}5 \\
(1 \cdot 4)\end{array}$ & 9 & 56 \\
\hline 21 & $\begin{array}{c}1 \\
(0 \cdot 6)\end{array}$ & 3 & $\begin{array}{l}20 \\
(2 \cdot 7)\end{array}$ & 69 & 0 & - & $\begin{array}{c}8 \\
(1 \cdot 0)\end{array}$ & 28 & $\begin{array}{c}3 \\
(0 \cdot 8)\end{array}$ & 10 & 29 \\
\hline 42 & $\begin{array}{c}1 \\
(0 \cdot 3)\end{array}$ & 17 & $\begin{array}{c}3 \\
(0 \cdot 5)\end{array}$ & 50 & 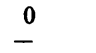 & - & $\begin{array}{c}2 \\
(0 \cdot 4)\end{array}$ & 33 & $\begin{array}{c}1 \\
(0 \cdot 5)\end{array}$ & 17 & 6 \\
\hline 84 & $(0 \cdot 1)$ & 14 & $\begin{array}{c}4 \\
(1 \cdot 0)\end{array}$ & 57 & $\begin{array}{c}0 \\
-\end{array}$ & - & $\begin{array}{l}2 \\
(1 \cdot 6)\end{array}$ & 29 & 0 & - & 7 \\
\hline
\end{tabular}

Cell counts and percentage proportions of inflammatory cells in the central stroma of corneas infected by Acanthamoeba. Neutrophils were stained with haematoxylin and eosin. Other inflammatory cell types were stained with monoclonal antibodies ED2 (macrophages), OX-33 (B cells), OX-19 (Tyes were stained with monoclonal antibodies ED2 (macrophages), OX-33 (B cells), OX-19 (T cells), and OX-39 (activated T cells). Positively stained cells were counted with a graticule at
magnification. Standard error of the cell count in three fields in each of two corneas is given in parentheses. The total cell number given excludes OX-39+ (activated T) cells, which are taken to be a subset of $O X-19+($ pan $T)$ cells.

By day 7 macrophages had become the predominant cell type, constituting $63 \%$ of all cells. By this time neutrophils had sharply declined in absolute numbers and proportion (15\%). $\mathrm{T}$ cells first appeared on day 7 .

On day 14 the total cell count was highest. Macrophages continued to be the predominant cell type (Fig 3A). T cells constituted $20 \%$ of cells, and activated $\mathrm{T}$ cells were identified for the first time (Fig 3B). This indicates that the OX$19+($ pan-T) cells observed in earlier sections are probably not specifically directed against Acanthamoeba antigen.

On days 21 and 42 neutrophils continued to decline in numbers; macrophages continued to be the predominant constituent inflammatory cell; $T$ cells and activated $T$ cells continued to be observed in the same proportions. By day 42 the total number of inflammatory cells had markedly declined. On day 84 macrophages and $T$ cells $(\mathrm{OX}-19+)$ persisted as the predominant cells in a sparse inflammatory infiltrate. Activated $T$ lymphocytes $(\mathrm{OX}-39+)$ were no longer identified.

Almost no B lymphocytes were observed at any time, with only a solitary cell being stained, on day 14 (Fig 3C).

\section{Discussion}

The extensive use of hybridoma technology has led to the development of new methods for the isolation of murine immunoglobulins from cell culture or ascites fluids. ${ }^{13}$ Monoclonal antibodies reactive with cell surface antigens have become

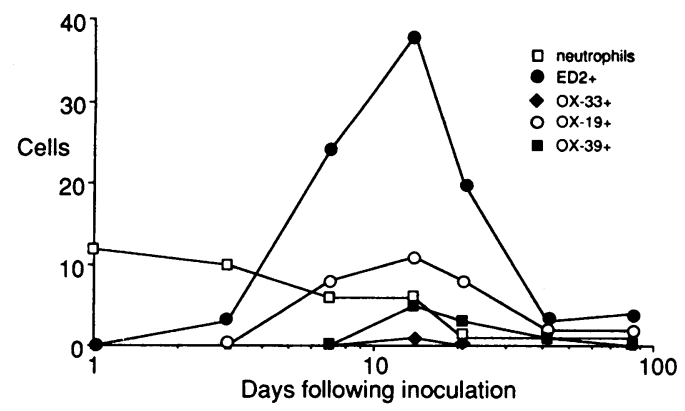

Figure 2A Differential inflammatory cell counts in infected corneas at intervals after inoculation of Acanthamoeba. Horizontal axis is log scale. the primary tools for study of inflammatory cell, and particularly lymphocyte, heterogeneity. Surface markers have rarely been found to be absolutely specific for any one inflammatory cell type. However, the specificity for rat inflammatory cells reported for those antibodies used in this study has led to their wide use in immunocytochemistry. Antibodies specific for rat T cel! individual subsets are not commercially available at the time of writing.

Immunohistochemical study of the immune response in Acanthamoeba keratitis is necessary because so many features of this infection suggest an unusual host response to the pathogen. These include poor response to amoebicidal drugs, ${ }^{4}$ chronic clinical course, lack of corneal vascularisation in human and experimental disease, ${ }^{67}$ and lack of lymphocyte response in human pathological studies. ${ }^{56}$

In experimental Acanthamoeba keratitis we have identified a dynamic process in which the inflammatory cell profile alters with time. The inflammatory cell population was observed to be entirely neutrophil on day 1 , with macrophages becoming the predominant cell type by day $7 . T$ cells, including activated $\mathrm{T}$ cells, were constituents of the immune response after the first week; B cells were conspicuously absent. The numerical increase in amoebae seen at day 3 may be due to excystment and trophozoite multiplication. Decline after this time probably reflects destruction by inflammatory cells. While the clinical severity of keratitis was maximal in the first week, and the number of Acanthamoeba in tissue sections appeared maximal at day 3 , the number of inflammatory cells was highest at day 14. These findings may indicate that amoebic destruction by the rat inflammatory response was maximal at around day 14. Destruction of amoebae was observed in sections at various time points but not quantified.

Immunohistochemical data from our study form an interesting contrast with those from two human corneal transplantation specimens reported by Mathers and colleagues. ${ }^{6}$ These authors found that $80 \%$ to $100 \%$ of cells near the site of corneal ulceration were neutrophils or macrophages; no B or T cells were found in one cornea, and $T$ cells constituting $10 \%$ with no $B$ cells in the other. In both human and animal disease the reason for the absence of $B$ cells in the inflammatory cell infiltrate is uncertain. It is unlikely that lack of corneal vascularisation explains the absence of $B$ cells. In a model of experimental keratitis in the rat induced by

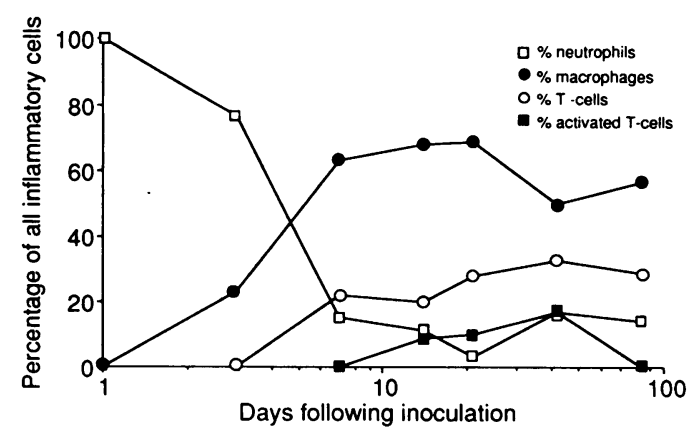

Figure $2 B$ Differential inflammatory cell percentage proportions. Horizontal axis is log scale. 
Figure 3 Frozen sections of rat central cornea 14 days after inoculation with Acanthamoeba. The sections were stained with monoclonal antibody: the brown colour indicates positive staining and the light purple colour is

haematoxylin counterstain. (A) ED2 staining of $a$ number of cells (small arrows) around

Acanthamoeba cysts (large arrow) $(\times 270)$. (B) MRC $O X-39$ staining of activated $T$ cells (arrow) in anterior stroma $(\times 170)$. (C) A solitary MRC OX-33 staining B cell (arrow) in deep stroma $(\times 170)$. This was the only cell observed in any section which stained with this antibody.

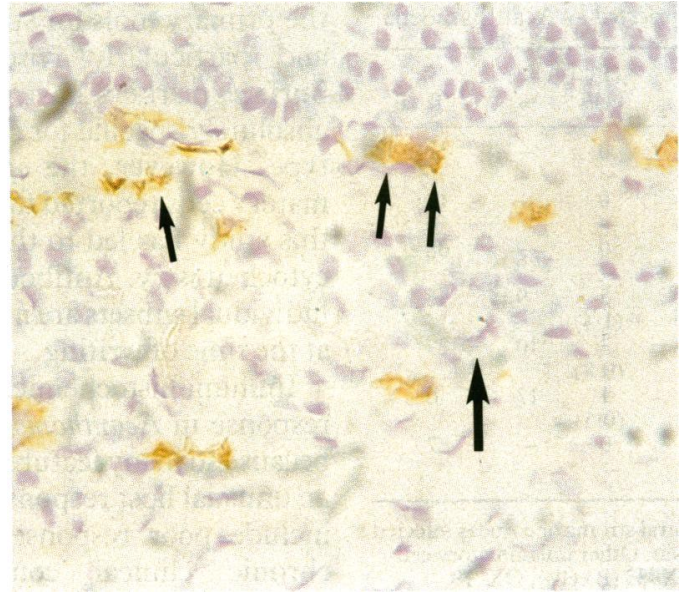

Figure 3A

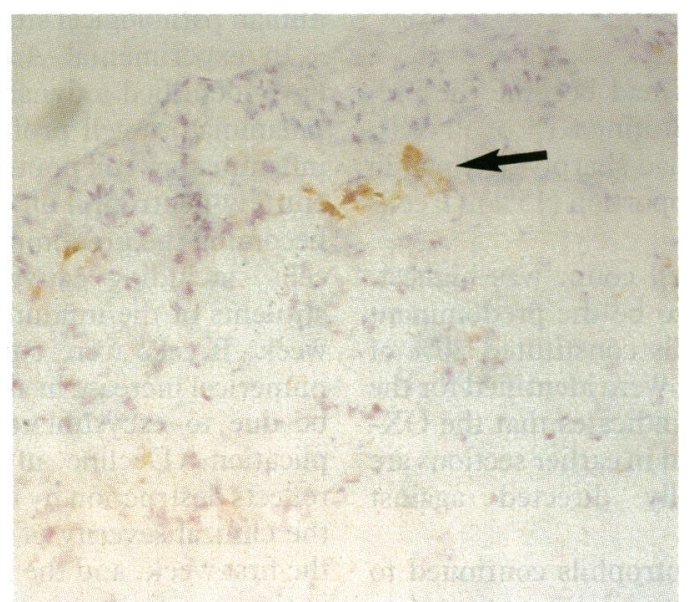

Figure 3B

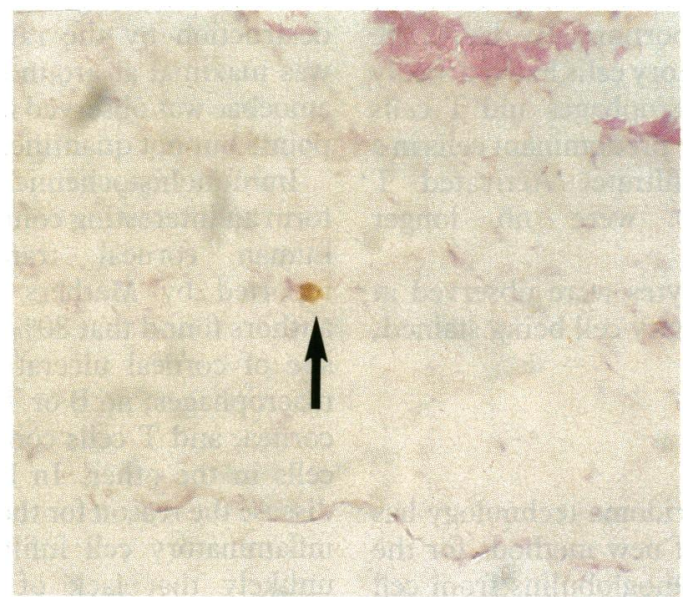

Figure 3C

intrastromal injection of heat inactivated rabbit serum Verhagen and colleagues observed corneal vascularisation but no B lymphocytes in the inflammatory infiltrate. ${ }^{14}$ In experimental Acanthamoeba infection it is, however, possible that there is systemic production of antibody without plasma cell or B cell infiltration into cornea. In this study we did not examine the serum for a measurable antibody response, which has been found in human infection. ${ }^{\text {is }}$
Immunological tolerance, the acquisition of non-reactivity towards particular antigens, may independently involve $B$ and $T$ cells and might explain the absence of B lymphocytes in the cornea. It might be that $B$ cells are immature in the 6-8-week old rat, and that $B$ cells encountering antigen for the first time become tolerant. Tolerance might also be mediated by soluble factors from suppressor $T$ cells, and antigen-specific suppressor $T$ cell-induced tolerance has been observed in mice. ${ }^{16}$ Finally, as normal $B$ cell responses to $T$-dependent antigens require help of specific $T$ cells, reduced production of $B$ cell maturation lymphokine IL- 4 by the $\mathrm{H}_{1}$ category of helper $\mathrm{T}$ cells might cause functional $B$ cell deletion.

Further studies are necessary to characterise more comprehensively the immune response to Acanthamoeba. We plan to survey infected rat cornea for $\mathrm{T}$ cell subsets and class II major histocompatibility complex (MHC) antigens which would indicate local presentation of antigen. It would also be informative to extend immunohistochemical study to the limbus and local lymph nodes.

The authors are grateful to Alcon Laboratories Ltd and the South-Western Regional Health Authority for financial support, and to Ian Williams for assistance with tissue staining.

1 Martinez AJ. Is Acanthamoeba encephalitis an opportunistic infection? Neurology 1980; 30: 567-74

2 Moore MB, McCulley JP, Newton C, et al. Acanthamoeba keratitis: a growing problem in soft and hard contact lens keratitis: a growing problem in soft and

3 Stehr-Green JK, Bailey TM, Visvesvara GS. The epidemiology of Acanthamoeba keratitis in the United States. Am $\mathcal{F}$ Ophthalmol 1989; 107: 331-6.

4 Auran JD, Starr MB, Jakobiec FA. Acanthamoeba keratitis. A review of the literature. Cornea 1987; 6: 2-26.

5 Garner A. Pathology of corneal acanthamoebic infection. In Cavanagh HD, ed. The cornea: Transactions of the World Congress of the Cornea III. New York: Raven, 1988: 535-9.

6 Mathers W, Stevens G, Rodrigues M, et al. Immunopathology and electron microscopy of Acanthamoeba keratitis. $A m \mathcal{F}$ Ophthalmol 1987; 103: 626-35.

7 Larkin DFP, Easty DL. Experimental Acanthamoeba keratitis: I. Preliminary findings. Br $\mathcal{F}$ Ophthalmol 1990; 74: 551-5.

8 Dijkstra CD, Döpp EA, Joling P, Kraal G. The heterogeneity of mononuclear phagocytes in lymphoid organs: distinct macrophage subpopulations in the rat recognized by monoclonal antibodies ED1, ED2 and ED3. Immunology 1985; 54: 589-99.

9 Dallman MJ, Thomas ML, Green JR. MRC OX-19: A monocloncal antibody that labels rat $T$ lymphocytes and augments in vitro proliferative responses. Eur f Immunol 1984; 14 260-7.

10 Woollett GR, Barclay AN, Puklavec M, Williams AF Molecular and antigenic heterogeneity of the rat leucocytecommon antigen from thymocytes and $\mathrm{T}$ and $\mathrm{B}$ lymphocommon antigen from thymocytes and

11 Paterson DJ, Jefferies WA, Green JR, et al. Antigens of activated rat $\mathrm{T}$ lymphocytes including a molecule of 50000 $M_{\mathrm{r}}$ detected only on CD4 positive T blasts. Molec Immunol 1987; 24: 1281-90.

12 Hsiung LM, Barclay AN, Brandon MR, Sim E, Porter RR. Purification of human C $3 b$ inactivator by monoclonal antibody affinity chromatography. Biochem $\mathcal{F} 1982 ; 203: 293-8$.

13 Burchiel SW, Billman JR, Alber TR. Rapid and efficien purification of mouse monoclonal antibodies from ascites fluid using high performance liquid chromatography. f Immunol Methods 1984; 69: 33-42.

14 Verhagen C, Hoekzema R, Breebaart AC, Kijlstra A. Immunohistological studies on experimental keratitis in the rat. Invest Ophthalmol Vis Sci 1990; 31 (suppl): 486.

15 Wright P, Warhurst D, Jones BR. Acanthamoeba keratitis successfully treated medically. Br $\mathcal{F}$ Ophthalmol 1985; 69: successf

16 Foster CS, Monroe JG, Campbell R, Kalpaxis J, Wetzig R, Greene MI. Ocular immune responses. II. Priming of $A / J$ mice in the vitreous induces either enhancement of or suppression of subsequent hapten-specific DTH responses. f Immunol 1986; 136: 2787-91. 